\title{
Adapting ANUGA model for border-check irrigation simulation
}

\author{
F. Githui $^{a}$, A. Hussain ${ }^{a}$ and M. Morris ${ }^{a}$ \\ ${ }^{a}$ Agriculture Research and Development, \\ Department of Economic Development, Jobs, Transport and Resources \\ Tatura, Victoria, Australia \\ Email:faith.githui@ecodev.vic.gov.au
}

\begin{abstract}
Infiltration is a major process in irrigation, varying over both time and space during irrigation events. To simulate infiltration in border-check surface irrigations, one-dimensional (1D) models are commonly used. However, 1D models cannot simulate surface irrigations adequately when the surface of the irrigation bay is not uniform or bay micro topography is modified to improve surface water drainage. The 2D surface water flow model ANUGA, developed by the Australian National University and Geoscience Australia was used to model border irrigation performance. Use of a 2D model is part of our research work that seeks to evaluate the performance of surface irrigation based on different micro topography bay designs with the aim of reducing water ponding on the bays and improving irrigation efficiencies. Although ANUGA has the capability of applying infiltration as 'negative' rainfall, it does not simulate soil water infiltration. Therefore, we developed an infiltration algorithm using the empirical Modified Kostiakov (MK) equation which calculates infiltration as a function of ponding time. Ponding time is the duration since the commencement of surface inundation, ending when inundation ceases. The MK equation could not be applied directly in ANUGA because different areas of the model domain commence ponding at different times and are ponded for different durations during a simulation. In addition, the infiltration depth calculated by the MK equation at a given time is sometimes greater than the water depth on the surface.
\end{abstract}

The ANUGA model is set up by defining a study area (called a 'domain' in ANUGA) represented by a mesh of triangular cells. The mesh attributes include the land elevation, water surface elevation and frictional resistance. In our algorithm, the model time step at which each triangular mesh cell first has surface water is stored as the start of ponding on that cell. Ponding duration is calculated for each cell as the time between the current model time step and the time step ponding commenced. Based on the ponding duration, an infiltration depth is calculated for each 'wet' mesh cell. If there is sufficient water on the cell to satisfy the current infiltration depth, this depth is subtracted by the rate operator from the surface water. If there is insufficient surface water on a cell, all surface water is removed and the remaining, unsatisfied infiltration depth is carried forward into the next model time step. The cell ponding duration is incremented only when the infiltration depth is less than the depth of water available on the surface. This approach ensures that the irrigation advance propagates through the triangular mesh at a rate constrained by infiltration.

The data used to set up and run an irrigation event in ANUGA included bay microtopography, inflow to the bay, Manning's roughness coefficient ' $n$ ' and infiltration parameters. Manning ' $n$ ' and infiltration parameters were obtained from the 1D SISCO model using the measured data of inflow to the bay, and water advance and depth data within the bay. The modelled outputs of water advance, depth hydrographs, infiltration and runoff volumes were compared with the measured data.

Results showed a reasonable agreement between measured and simulated water depth hydrographs, measured and predicted water advance, runoff volume and cumulative infiltration. This study showed that the implementation of the MK infiltration algorithm in ANUGA was successful and that the adapted ANUGA model adequately simulated a border-check surface irrigation.

Keywords: Surface irrigation, 2D model, Kostiakov 


\section{INTRODUCTION}

In border-check irrigation systems fields are divided with low check banks into smoothly graded, rectangular bays. Water is applied at the top of each bay from a farm channel outlet at an inflow rate and over a duration known to be sufficient to irrigate the entire bay without excessive runoff. Runoff is collected by surface drains at the foot of the irrigation bay. A water advance phase occurs during irrigation, ending when the irrigation supply is cut off, before surface water reaches the end of the bay. The depletion phase follows until the depth of water at the top of the bay reduces to zero, when the recession phase commences and lasts until surface water flow ceases. Runoff usually occurs during the recession phase.

Surface irrigation is commonly simulated using one dimensional (1D) models. These models assume that the irrigation bay surface is perfectly smooth and that the spread of water is uniform. Though irrigation bays are usually laser graded, in reality perfectly smooth irrigation bay surfaces do not exist and even a precisely graded bay surface degrades with time to become non-uniform. 1D-models cannot successfully simulate the effects of a non-uniform surface on flow pathways within bays or the formation of puddles which become pronounced especially after irrigation cut-off. Therefore we have chosen the 2D ANUGA, an open source model developed by the Australian National University and Geosciences Australia. Although ANUGA was specifically written to simulate tsunamis, it has the potential to simulate a wide range of water flow scenarios (Van Drie et al. 2008). ANUGA applications include studies such as Martin et al. (2014) who simulated combined storm tide and riverine flooding, Van Drie et al. (2011) who simulated flood levels and reproduced the hydrologic response of a catchment and Roberts et al. (2008) who simulated a tsunami striking the Queensland coastline. The model has also been used to simulate flow through structures such as culverts, bridges and dams. To our knowledge, there is no reported literature on the use of ANUGA for irrigation modelling. The choice and use of ANUGA is part of our research work that seeks to evaluate the performance of surface irrigation based on different micro topography bay designs with the aim of reducing water ponding on the bays and improving irrigation efficiencies.

In our study, we used the 1D SISCO model (Gillies and Smith, 2015) to provide infiltration parameters for use in ANUGA. SISCO has been successfully used for estimating bay irrigation performance of pasture in northern Victoria (Morris et al. 2015). SISCO uses the 1D form of the Saint-Venant equations and estimates the modified Kostiakov (MK) infiltration parameters and Manning roughness coefficient for an irrigation event simulation. It does this by minimizing the difference between measured and predicted data using as the objective function, the sum of squares of the difference between measured and predicted data divided by sum of squares of measured data. The numerical approach used to solve the hydrodynamic equations in SISCO is similar to the Eulerian integration as described by Walker and Skogerboe (1987) which uses a deformable control volume. In the Eulerian approach for sequential time steps, field length is divided into a series of stationary cells which are determined during the advance phase, thus forming a time-distance grid. Continuity and momentum equations are solved simultaneously for each cell for a given time step. SISCO uses semifixed time steps where it will temporarily reduce the time step if the volume balance error is large or the model fails to converge.

In contrast, ANUGA solves the 2D Saint-Venant equations based on a finite-volume method using an unstructured grid. Whereas the cell locations and size in SISCO are determined during the irrigation advance to accommodate the calculated infiltration, cells in ANUGA are created before the simulation starts. This difference between the two models had to be accommodated in the way the MK equation was applied in ANUGA because the infiltration calculated by MK can be greater than the depth of water available on the surface at a given time step in ANUGA. In their review of irrigation systems modelling, Khanna and Malano (2005) showed that when this happens, some models reset the flow depth to an initial value which would lead to a mass balance error due to the negative depth. To correct this, the infiltration depth would then be equated to the flow depth and a new opportunity time determined. In this study we developed an algorithm in which the opportunity time is 'lagged' until the infiltration calculated by the MK equation is all used up before advancing to the next opportunity time and the flow depth is not reset. This ensures no errors in the mass balance occur. This algorithm is explained in more detail in the methodology section.

The aim of this paper was to present the implementation of the MK-based infiltration function in ANUGA in order to simulate border-check irrigation. The success of the implementation of the infiltration function was assessed by comparing the performance of ANUGA with the SISCO model for an irrigation event on a relatively smooth bay. 


\section{METHODOLOGY}

\subsection{Brief description of ANUGA model}

A brief description of ANUGA is presented here. The reader is referred to the ANUGA User Manual 1.3.0 and website (https://anuga.anu.edu.au) for a more detailed description. ANUGA is a hydrodynamic modelling tool that simulates flow in complex 2D geometries and is based on a finite-volume method for solving the shallow water wave equation. An ANUGA model is set up by defining a study area (called a 'domain' in ANUGA) represented by a mesh of triangular cells. The mesh attributes include the land elevation, water surface elevation and frictional resistance. Initial values for attributes such as water height and the domain boundary conditions must be specified and external effects such as rainfall, inflows, wind stress, water abstraction (including infiltration) and atmospheric pressure gradients can be applied. Once the setup is complete, the model is run over time steps with water depth and horizontal momentum through the triangular mesh tracked over time. ANUGA outputs can be interrogated to extract information such as water velocity and depth at specified locations over time, flow through cross sections, inundation maps and much more.

\subsection{Adapting ANUGA for border-check irrigation modelling}

ANUGA has been developed as a general purpose surface water flow model and therefore it forms a useful basis for a surface irrigation model. However, we have had to incorporate an infiltration function to simulate infiltration on an irrigated bay. Even though ANUGA has spatial-temporal operators that can apply infiltration as 'negative' rain over the model domain, it does not simulate vertical flow below the surface as happens when water moves through the soil profile. Therefore, we developed a spatial-temporal algorithm that mimics infiltration characteristics of a given soil type as water flows over the irrigation bay. This algorithm was written as a PYTHON function which generates an array of infiltration rates for wet cells at each model time step. This array is then passed on to the spatial-temporal "Rate Operator" in ANUGA which multiplies the infiltration rates by the time step, yielding infiltration depths. ANUGA then subtracts these infiltration depths from the depth of water on the bay for all the wet cells and calculates the new water depths for that time step. To this end, we selected the commonly used modified Kostiakov (MK) infiltration equation to model infiltration but adapted it to ensure that infiltration started at the time that the irrigation advance arrived at each point, and then proceeded at a rate that is related to the duration of water ponding at each point.

The cumulative form of the MK equation is given as:

$$
Z=k t^{a}+f_{o} t+C
$$

Equation 1

where $Z$ is the cumulative infiltration $(\mathrm{mm}), t$ is the opportunity time $(\mathrm{min}), f_{o}$ is a minimum final infiltration rate $(\mathrm{m} / \mathrm{min}), a$ and $k$ are empirical parameters; $a$ is dimensionless, $k$ is in $\mathrm{m} / \mathrm{min}^{\mathrm{a}}$, and $\mathrm{C}$ is a term that can account for initial 'instantaneous' infiltration through macropores and by adsorption. In the MK equation $a$, $k, f_{o}$ are optimized using measured data for a given irrigation event.

The algorithm calculates infiltration as a function of the ponding duration of each mesh cell. Direct application of the MK equation is complicated because each cell of the model domain can commence ponding at a different time and can be ponded for a different duration. In addition, the infiltration depth calculated by the MK equation for a cell at a given time can often be greater than the available surface water depth on the cell.

As irrigation water advances down the field, the model time step at which each triangular mesh cell first has surface water is stored as the start of ponding on that cell. Ponding duration is calculated for each cell as the time between the current model time step and the time step ponding commenced. Based on the ponding duration, an infiltration depth is calculated for each 'wet' mesh cell. If there is sufficient water on the cell to satisfy the current infiltration depth, this depth is subtracted by the rate operator from the surface water. If there is insufficient surface water on a cell, all surface water is removed and the remaining, unsatisfied infiltration depth is carried forward into the next model time step. The cell ponding duration is incremented only when the infiltration depth is less than the depth of water available on the surface. This approach ensures that the irrigation advance propagates through the triangular mesh at a rate constrained by infiltration. 


\subsection{Data and ANUGA model setup}

The data shown in Table 1 was used to set up an irrigation bay model for a bay in northern Victoria. The bay topography and GPS data were collected using a Trimble total station (http://www.trimble.com/Survey/Total-

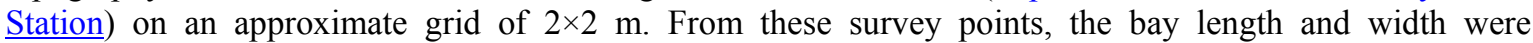
determined. Inflow to the bay was measured at the farm outlet by a magnetic flow meter. Surface water depth within the bay was measured by with five capacitance depth meters evenly spaced at 50, 100, 150, 200 and $245 \mathrm{~m}$ distances from the top of the bay. Runoff was measured by an acoustic doppler meter installed in the surface drain at the end of the bay.

Table 1. Data and information used for model set up.

\begin{tabular}{|c|c|}
\hline Bay length x width (m) & $253 \times 39$ \\
\hline Average bay slope $(\mathrm{m} / \mathrm{m})$ & 0.0015 \\
\hline Surface elevations survey grid & $2 \times 2 \mathrm{~m}$ \\
\hline Total irrigation event duration (hr) & 30 \\
\hline Irrigation inflow duration (min) & 74 \\
\hline Average inflow rate $\left(\mathrm{m}^{3} / \mathrm{s}\right)$ & 0.137 \\
\hline \multicolumn{2}{|l|}{ MK equation parameters: } \\
\hline$a$ & 0.168 \\
\hline$k(\mathrm{~mm} / \mathrm{hr})$ & 30.947 \\
\hline$f_{0}(\mathrm{~mm} / \mathrm{hr})$ & 0.0 \\
\hline$C(\mathrm{~mm})$ & 0.0 \\
\hline Manning's n & 0.2 \\
\hline
\end{tabular}

The SISCO model was run to calibrate infiltration parameters which were then used in ANUGA to simulate the irrigation event. The outputs of water advance, depth hydrographs, infiltration and runoff volume from both models were compared with field measurements. Measures to evaluate model performance were the Nash Sutcliffe efficiency (NSE), percent bias (PBIAS) and RMSE-observations standard deviation ratio (RSR) where RMSE is the Root Mean Squared Error (Moriasi et al. 2007).

\section{RESULTS AND DISCUSSION}

Overall, the ANUGA water depth hydrographs matched measured depth hydrographs reasonably well .Figure 1 shows measured versus modelled depth hydrographs at all logger locations on the bay $\left(R^{2}=0.82, \mathrm{NSE}=\right.$ 0.80, PBIAS $=-3.6$ and $\mathrm{RSR}=0.28$ ).

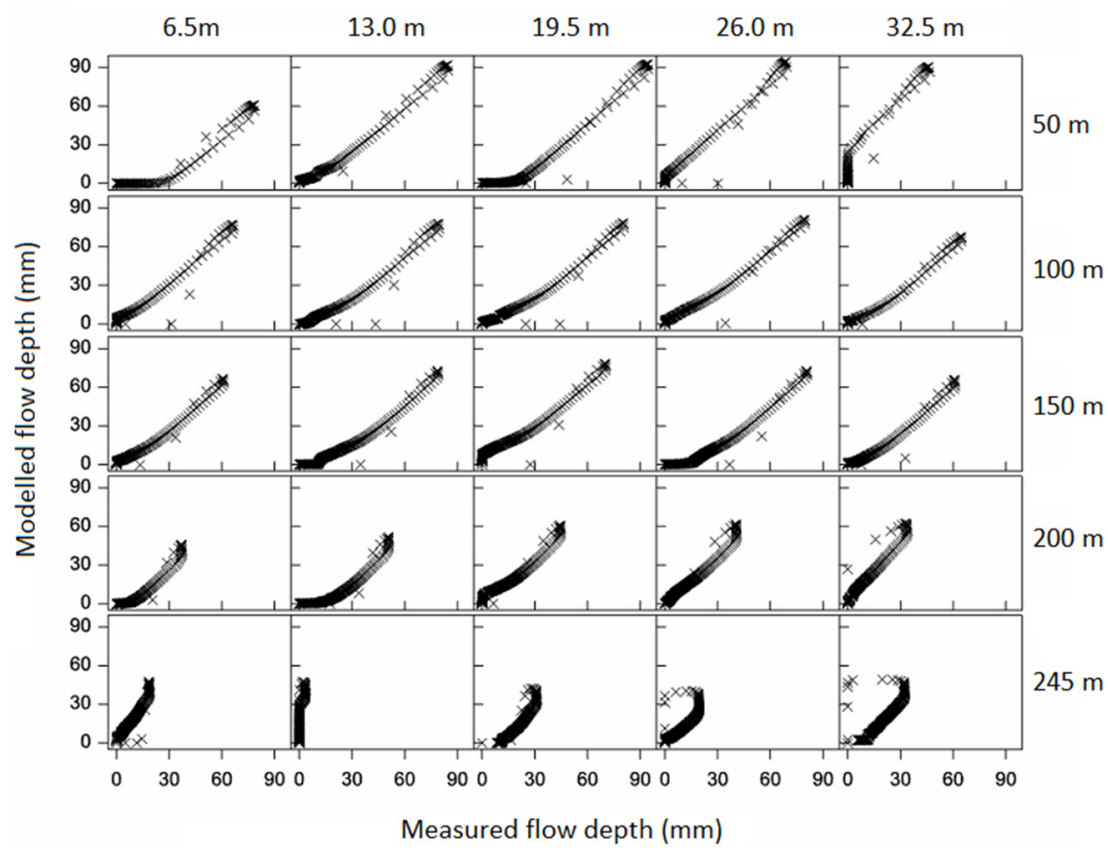

Figure 1. Measured versus ANUGA modelled depth hydrographs measured on the irrigation bay at distances down the bay $(50,100,150,200,245 \mathrm{~m})$ and across $(6.5,13.0,19.5,26.0$, and $32.5 \mathrm{~m})$. 
Some depth hydrographs towards the end of the bay were not simulated as well as those on the higher parts of the bay. This is probably more an artifact of the SISCO infiltration parameters and Manning's friction coefficient ' $n$ ' than an inability of ANUGA to capture the flow depths. The SISCO model uses a single ' $n$ ' value and is unable to account for the slow movement of water at some stage after water advance reaches the end of the bay and when water depth recession starts to slow substantially, therefore all water depth hydrographs are truncated at that stage in the calibration of infiltration parameters. However, even with the parameters obtained from SISCO, ANUGA simulates most of the flow dynamics reasonably well. A sensitivity analysis on the infiltration parameters showed that the Manning's ' $n$ ' was more sensitive than $a$ and $k$ infiltration parameters. It is possible that the results towards the end of bay could be improved by using a variable ' $n$ ' over the domain because ' $n$ ' is related to the speed and depth of flow which both decrease with distance down the bay and with time as surface water drains.

To compare results with SISCO, we averaged the ANUGA predicted water depth, advance and cumulative infiltration at each measured distance down the bay. The goodness of fit statistics also showed that average depth hydrographs in ANUGA performed better (higher NSE and lower PBIAS and RSR) compared to SISCO (Table 2). While there was a good agreement between SISCO and ANUGA in water advance, there was more variability observed in cumulative infiltration in ANUGA (Figure 2). ANUGA is able to retain water on the surface of low-lying areas as puddles, which SISCO cannot do. Even though both models underestimated measured flow depth, ANUGA performed much better with PBIAS of -5.8 compared to SISCO's -15.6.

Table 2. Model evaluation statistics comparing average depth hydrographs with measured data.

\begin{tabular}{lrrr}
\cline { 2 - 4 } & PBIAS & RSR & NSE \\
\hline ANUGA & -5.82 & 0.30 & 0.91 \\
SISCO & -15.57 & 0.34 & 0.89 \\
\hline
\end{tabular}
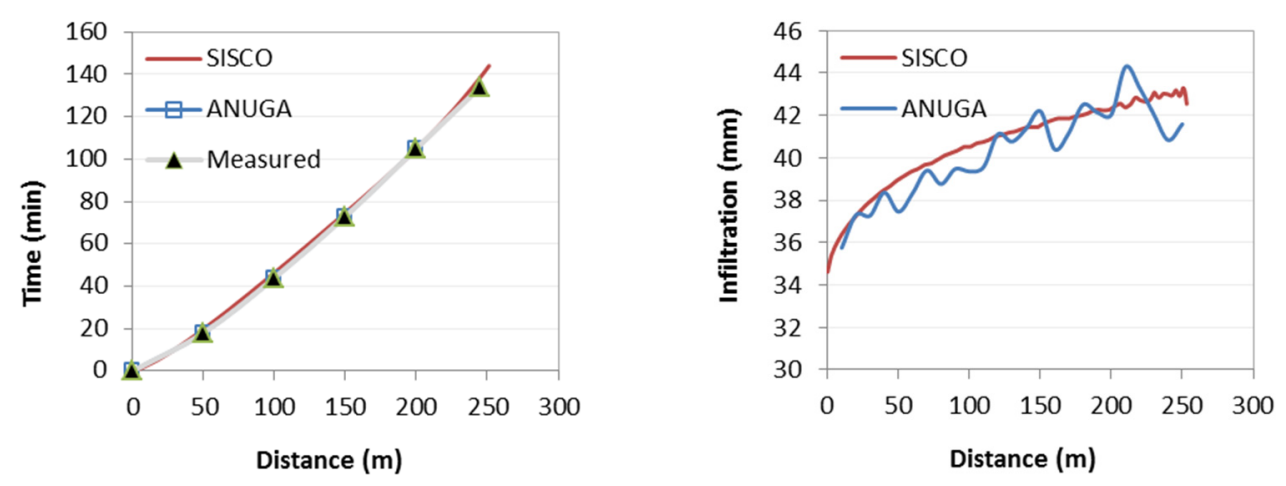

Figure 2. Left: Model advance with time; Right: Infiltration depth (averaged across the bay) with distance.

The models' total runoff volume matched well with the measured runoff (Table 3 ), however the model hydrographs time series deviated from the measured one (Figure 3). This deviation is likely due to the use of the constant Manning's ' $n$ ' in addition to the fact that the runoff volume is instantaneously recorded in ANUGA when it runs off the edge of the bay while the measured runoff rate depends on the drain dimensions, slope of the drain and the position in the drain where runoff was measured. It is difficult to represent a drain at the end of the bay with this lagged water flow in ANUGA. The slight differences in inflow volumes are attributed to the different ways the two models interpolate inflow within the first and last time intervals of the inflow time series based on the model time step used (Table 3). 
Githui et al., Adapting ANUGA model for border-check irrigation modelling

Table 3. Model water balance and measured inflow and runoff.

\begin{tabular}{lrrrc}
\cline { 2 - 5 } & $\begin{array}{r}\text { Inflow } \\
\left(\mathrm{m}^{3}\right)\end{array}$ & $\begin{array}{r}\text { Runoff } \\
\left(\mathrm{m}^{3}\right)\end{array}$ & $\begin{array}{r}\text { Infiltration } \\
\left(\mathrm{m}^{3}\right)\end{array}$ & $\begin{array}{r}\text { Ponded water } \\
\left(\mathrm{m}^{3}\right)\end{array}$ \\
\hline ANUGA & 598.7 & 200.4 & 397.3 & 0.9 \\
SISCO & 601.0 & 197.5 & 402.3 & \\
Measured & 599.6 & 197.4 & & \\
\hline
\end{tabular}

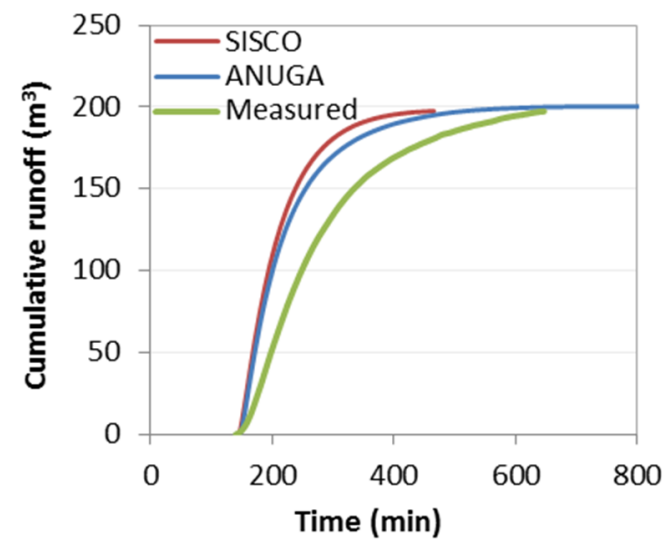

Figure 3. Cumulative runoff volume from SISCO, ANUGA and field measurements.

While ANUGA is able to determine the amount of water ponded on the surface at the end of the simulation, SISCO assumes no water is left standing. One advantage of ANUGA over SISCO is the ability to see how the bay performs spatially, for example, infiltration and the duration of water ponding on the bay (Figure 4). With ANUGA we also have the ability to assess the performance of alternative bay designs that would not be simulated with a $1 \mathrm{D}$ model.
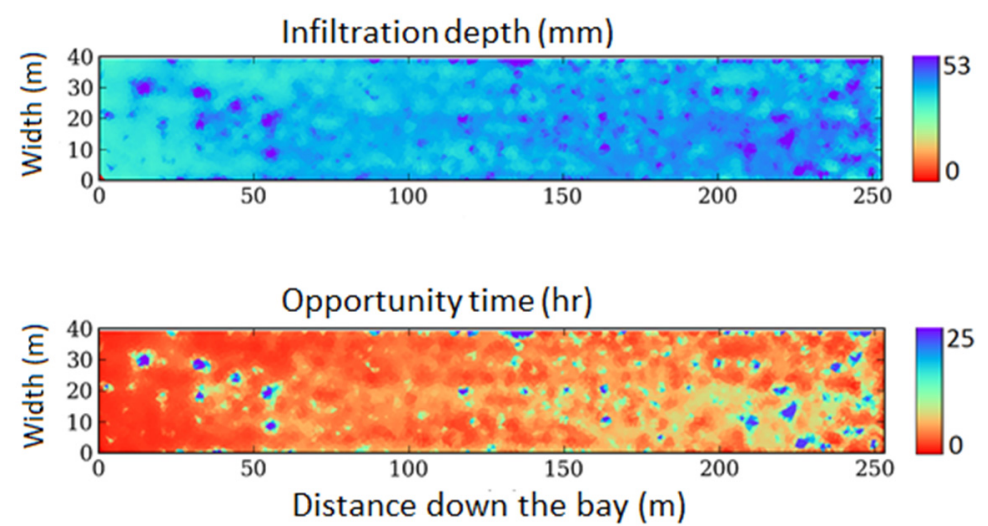

Figure 4. Bay infiltration (mm) and opportunity time (hr).

\section{CONCLUSION}

Results from this study have shown that ANUGA, adapted with a suitable infiltration operator, can usefully simulate surface irrigation. It is likely that the results can be improved by optimizing the infiltration parameters in ANUGA as well as using a variable Manning's ' $n$ '. This infiltration algorithm is attractive because if the MK parameters are available from another model, they can be used to give quick estimates without having to calibrate the ANUGA model. ANUGA has the capability to predict spatial and temporal 
water distribution and infiltration in any part of the bay. In particular two dimensional models such as ANUGA can be used to study the water distribution and irrigation performance on non-uniform bay surfaces.

Future work will involve using ANUGA to assess the irrigation performance of bays with modified micro topography which the $1 \mathrm{D}$ models cannot do.

\section{REFERENCES}

Gillies, M.H., and R.J. Smith. (2015). SISCO-Surface irrigation simulation calibration and optimisation. Irrigation Science. DOI 10.1007/s00271-015-0470-8.

Khanna, M.H., and M. Malano. (2005). Modelling of basin irrigation systems: A review. Agricultural Water Management, 83(1-2), 87-99.

Martin, S., D. Moore., and M. Hazelwood. (2014). Coastal inundation modelling for Busselton, Western Australia, under current and future climate. Record 2014/03. Geoscience Australia: Canberra. http://dx.doi.org/10.11636/Record.2014.003

Moriasi, D.N., J.G. Arnold., M.W. Van Liew., R.L. Bingner., R.D. Harmel., and T.L.Veith. (2007). Model evaluation guidelines for systematic quantification of accuracy in watershed simulations. Transactions of the ASABE 50(3), 885-900.

Morris, M.R., A. Hussain., M.H. Gillies., and N.J. O’Halloran. (2015). Inflow rate and border irrigation performance. Agricultural Water Management, 155(2015), 76-86.

Roberts, S.G., O.M. Nielsen., and J. Jakeman. (2008). Simulation of tsunami and flash floods. In: modeling, simulation and optimization of complex processes. 2008, 489-498.

Van Drie, R., M. Simon., and I. Schymitzek. (2008). 2D hydraulic modelling over a wide range of applications with Anuga. Paper presented at 9th National Conference on Hydraulics in Water Engineering, Darwin Convention Centre, Australia 23-26 September 2008.

Van Drie, R., P. Milevski., and M. Simon. (2011). Validation of a 2-D hydraulic model - Anuga, to undertake hydrologic analysis [online]. In: Valentine, EM (Editor); Apelt, CJ (Editor); Ball, J (Editor); Chanson, H (Editor); Cox, R (Editor); Ettema, R (Editor); Kuczera, G (Editor); Lambert, M (Editor); Melville, BW (Editor); Sargison, JE (Editor). Proceedings of the 34th World Congress of the International Association for Hydro- Environment Research and Engineering: 33rd Hydrology and Water Resources Symposium and 10th Conference on Hydraulics in Water Engineering. Barton, A.C.T. Engineers Australia, 2011: 450457.

Walker, W.R., and G.V. Skogerboe. (1987). Surface irrigation: theory and practice. Prentice-Hall, Englewood Cliffs, New Jersey. 